Received Date : 04-Oct-2016

Revised Date : 17-Oct-2016

Accepted Date : 18-Oct-2016

Article type : Mini-review

\title{
MINI-REVIEW
}

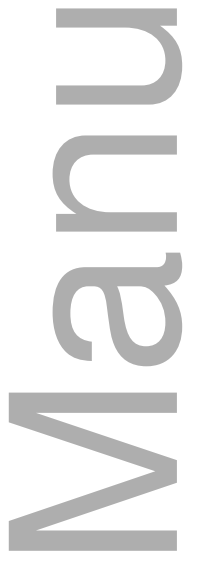

\section{Recent advances in regenerative medicine to treat enteric neuropathies: Use of human cells}

LINCON A. STAMP \& HEATHER M. YOUNG

Department of Anatomy \& Neuroscience, University of Melbourne, 3010, VIC, Australia

This is the author manuscript accepted for publication and has undergone full peer review but has not been through the copyediting, typesetting, pagination and proofreading process, which may lead to differences between this version and the Version of Record. Please cite this article as doi: $10.1111 / \mathrm{nmo} .12993$

This article is protected by copyright. All rights reserved 

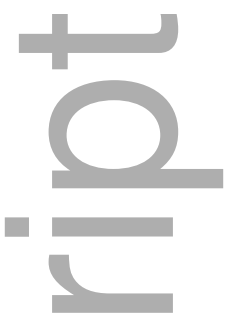

7

Address for correspondence: Lincon Stamp, PhD, Department of Anatomy and Neuroscience, University of Melbourne, 3010, VIC, Australia. Tel: +61 383445783, e-mail: Istamp@unimelb.edu.au

Key points

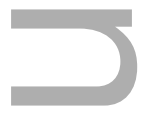

- Enteric neuropathies are challenging conditions to treat. As a result, many laboratories are using animal models to explore the potential of cell therapy to treat enteric neuropathies.

- Enteric neural progenitors can be isolated from the bowel of laboratory animals and infant and adult humans. Enteric neural progenitors can also be derived from human pluripotent stem cells.

- Human enteric neural progenitors migrate and undergo neuronal differentiation following transplantation into the bowel of animal models.

- Priorities for future research include improved methods for isolating enteric neural progenitors from the human bowel and then expanding and manipulating them in vitro, and the development of methods to introduce cells into the human bowel.

\section{Abstract}

As current options for treating most enteric neuropathies are either non-effective or associated with significant ongoing problems, cell therapy is a potential attractive possibility to treat congenital and acquired neuropathies. Studies using animal models have shown that following transplantation of enteric neural progenitors into the bowel of recipients, the transplanted cells migrate, proliferate and generate neurons that are electrically active and receive synaptic inputs. Recent studies have 
transplanted human enteric neural progenitors into the mouse colon and shown engraftment. In this article, we summarize the significance of these recent advances and discuss priorities for future research that might lead to the use of regenerative medicine to treat enteric neuropathies in the clinic.

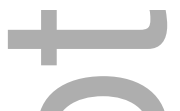

Key words Neural crest, cell therapy, Hirschsprung disease, cell transplantation

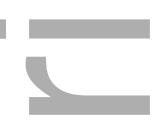

INTRODUCTION

The enteric nervous system (ENS) regulates a variety of GI functions, and plays an essential role in the control of motility in the small and large bowel. ${ }^{1}$ As a result, developmental or acquired defects in the ENS result in motility disorders. ${ }^{2,3}$ Most of the ENS arises from vagal neural crest cells in the caudal hindbrain that migrate into, and then along, the developing gut. ${ }^{4}$ The best characterized developmental enteric neuropathy is Hirschsprung Disease, in which neurons are absent from the distal bowel due to a failure of neural crest cells to colonize the complete GI tract. ${ }^{5-8}$ Like many diseases of the nervous system, most enteric neuropathies have severe effects on quality of life, but there are limited or no effective pharmacological treatments. ${ }^{2,3}$ Cell therapy is therefore an attractive, potential option for treating enteric neuropathies., ${ }^{90}$ Animal model studies investigating the potential of cell transplantation to treat Parkinson Disease commenced in the early 1980 's, and the first clinical trials involving the transplantation of fetal cells into the brains of patients with Parkinson Disease commenced later in the same decade. ${ }^{11}$ In contrast, the first animal model study to investigate the potential of cell therapy to treat a GI motility disorder was not published until 2005. ${ }^{12,13}$ Nonetheless, since then, steady progress has been made overcoming hurdles on the road towards developing cell-based therapies to treat enteric neuropathies. ${ }^{14}$ This mini-review accompanies an article by Cooper et a ${ }^{15}$ showing that ENS cells isolated from the fetal human bowel engraft and respond to electrical stimulation following transplantation into the mouse colon. We provide an overview of the identification and isolation of neural stem cells in the bowel, summarize key studies that have examined the potential of cell therapy to treat enteric neuropathies using animal models, discuss recent studies that have examined the potential of human enteric neural progenitors to survive, migrate and generate neurons in animal models, and finally discuss priorities for future research. 


\section{Neural stem cells can be isolated from the bowel of young and adult laboratory animals}

Cell therapy for enteric neuropathies requires a source of ENS progenitors. In 2002, Sean Morrison's laboratory ${ }^{16,17}$ was the first to show that multipotent cells capable of generating multiple neuronal sub-types and glia could be isolated from the small intestine of postnatal and adult rats using flow cytometry and expression of particular cell surface markers. The following year, a study from the laboratory of Vassilis Pachnis ${ }^{18}$ showed that cultures of dissociated postnatal mouse gut form neurosphere-like aggregates, similar to the neurospheres formed by CNS neural stem cells, when cultured in medium known to promote the growth of neural crest stem cells. These enteric "neurosphere-like bodies" (NLBs) contain progenitors that give rise to glial cells and multiple subtypes of neurons. ${ }^{18}$ NLBs can also be generated from isolated myenteric ${ }^{19}$ and submucosal ganglia ${ }^{20}$ from adult and postnatal rats, although NLBs generated from the myenteric plexus occur at higher density and exhibit higher proliferation rates than NLBs generated from the submucosal plexus. ${ }^{20}$ Enteric neural progenitor cell number can be expanded by dissociation of NLBs and repeated passage, although a recent study of NLBs generated from the outer layers of the rat gut showed that the proliferation rate was reduced with passage number. ${ }^{21}$

Formation of NLBs from dissociated gut cells is now a common method to isolate and study enteric neural progenitors. ${ }^{22-28}$ However, a recent study showed that not all NLBs of cells that form in cultures of dissociated gut cells contain neural stem cells and not all NLBs give rise to neural derivatives under differentiation conditions. ${ }^{29}$ Furthermore, NLBs generated from the outer layers of small intestine of adult mice contain more neural crest-derived cells than NLBs generated from the large intestine. ${ }^{28}$ Because not all cells within NLBs are of ENS origin, cell sorting is necessary to study pure populations of ENS-derived cells and to avoid transplantation of non-ENS cell types in transplantation studies. Modifications of the flow cytometry method originally developed by the Morrison laboratory are also still in use to isolate enteric neural progenitors ${ }^{30,31}$, while several laboratories, including our own, use mice in which all neural crest-derived cells express geneticallyencoded fluorescent proteins and flow cytometry to isolate ENS cells. ${ }^{29,32-35}$

\section{In vivo transplantation of enteric neural progenitors from laboratory animals}

Numerous laboratories have successfully transplanted neural progenitors isolated from the bowel of embryonic and postnatal mice and rats into the bowel of recipient, postnatal, wild-type mice and rats. ${ }^{24-26,30,32,34,35}$ These studies have consistently shown that, following transplantation, enteric neural progenitors proliferate, migrate, differentiate into glial cells and different neuron sub-types, form ganglia and show long-term survival. Importantly, the transplanted cells do not form tumours or spread to other organs. ${ }^{32,35}$ During early stages of ENS development, cells can express neuronal markers without being electrically excitable. ${ }^{36}$ However, the neurons generated from transplanted 
progenitors have been shown to fire action potentials, receive synaptic inputs and exhibit increases in intracellular $\mathrm{Ca}^{2+}$ in response to electrical stimulation, ${ }^{32,35}$ which are all hallmarks of functional neurons.

Enteric neural progenitors have also been transplanted into the aganglionic region of Hirschsprung model mice where they migrate and differentiate into neurons. ${ }^{25,32,35}$ However, an important but still unanswered question is whether transplanted progenitors migrate and generate enteric neurons as effectively in the aganglionic colon of Hirschsprung model mice as they do in the ganglionic colon?

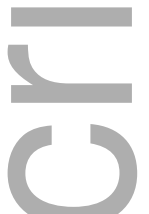

ISOLATION AND TRANSPLANTATION OF ENTERIC NEURAL STEM CELLS FROM HUMANS

\section{Neural stem cells can be isolated from the normal and aganglionic bowel of humans}

The methods used to form NLBs from dissociated postnatal rodent gut were adapted to full thickness bowel samples from human fetuses and segments of external muscle and myenteric plexus of infant human bowel. ${ }^{37,38}$ When cultured under appropriate conditions, dissociated human gut cells were shown to form NLBs that contain proliferating cells as well as cells expressing a variety of neuron sub-type markers. ${ }^{38,39}$ Moreover, NLBs generated from the colon of neonates ${ }^{40}$ and children $^{41}$ can be expanded in culture over multiple passages.

NLBs can also be generated from gut mucosal tissue from infants, children and teenagers obtained using routine endoscopy. ${ }^{42}$ This was a very important finding as it showed that enteric neural progenitors could be obtained from humans using minimally invasive techniques and that enteric neural progenitors are not restricted to the ganglionated layers of the human bowel. ${ }^{42}$ The latter finding is perhaps not surprising as although nerve cell bodies are restricted to myenteric and submucosal ganglia in laboratory animals, there are several reports of neurons or "neuroglial" cells in the mucosa of the human bowel. ${ }^{43,44}$ NLBs containing enteric neural progenitors can even be obtained from the aganglionic region of infants with Hirschsprung disease, ${ }^{45}$ which could be an important source of cells for autologous transplantation. The source of neural stem cells in the aganglionic region of bowel in Hirschsprung disease patients is likely to be sacral neural crest cells, and/or Schwann cell precursors associated with extrinsic nerves as Schwann cell precursors have been shown to give rise to some enteric neurons in the developing mouse. ${ }^{46}$

Because NLBs generated from dissociated human gut cells are likely to include non-ENS cells, two recent studies have sorted ENS cells from the human bowel using flow cytometry after immunolabelling with the neurotrophin receptor, p75, a markers of neural crest cells. Cooper et $\mathrm{al}^{15}$ used fetal human gut tissue while Rollo et al ${ }^{47}$ used dissociated ganglionic bowel from the proximal 
margin of colon tissue resected from Hirschsprung disease infants as the source of neural progenitors. ENS cells were found to be harvested with greater efficiency from the fetal human gut than from postnatal human gut. ${ }^{15}$ The proliferation rate of cultured p75-positive cells isolated from the Hirschsprung patient bowel tissue was found to be low, but could be improved by pharmacological enhancement of Wnt signaling. ${ }^{47}$ This study demonstrates that although ENS progenitors can be purified from human Hirschsprung infant bowel tissue, they will require manipulation in order to expand the population prior to transplantation.

It would be intriguing to compare the proliferative and differentiation abilities of neural progenitors isolated from the ganglionic region of bowel of a patient with Hirschsprung disease with those isolated from the aganglionic bowel region of the same patient. Studies using animal models have reported differences in the properties of enteric neural stem cells, including their frequency and their proliferative and neurogenic capabilities that vary with the layer of the gut from which the cells are isolated and the age of the donor animal, ${ }^{20,48}$ but similar systematic comparisons have not yet been made using human cells. However, a recent study compared NLBs generated from the ileum and caecum of a single patient that underwent ileocaecal resection and found a higher percentage of cell expressing neural crest markers in NLBs derived from the ileum than from the caecum. ${ }^{28}$

\section{ENS progenitors can also be derived from human pluripotent stem cells}

Using knowledge of the genes and factors involved in vagal neural crest cell identity, Fattahi and colleagues recently described protocols for deriving and isolating ENS progenitors from human pluripotent stem cells, including both embryonic stem cells and induced pluripotent stem cells. ${ }^{49}$ The ENS progenitors derived from human pluripotent cells expressed genes known to be expressed by ENS progenitors, including RET and EDNRB, and following injection into vagal levels of chick embryos, the progenitors migrated into and along the gut. ${ }^{49}$ Moreover, when cultured under differentiation conditions, the ENS progenitors differentiated into neurons expressing a variety of ENS neurotransmitter phenotypes. ${ }^{49}$ This study is highly significant, not only because ENS progenitors derived from human pluripotent stem cells are a potential source of cells for therapeutic purposes, but because the progenitors could also be used to study human ENS development and for generating human enteric neurons for drug testing.

\section{In vivo transplantation of human enteric neural progenitors into the bowel of laboratory animals}

One of the challenges of transplanting human enteric neural progenitors is identification of the cells following transplantation. Approaches that have been used to label human enteric neural progenitors prior to transplantation include transduction with lentiviral vectors expressing

fluorescent reporter genes ${ }^{15,47,50}$, and exposure to a fluorescent mitochondrial stain. ${ }^{47}$ 
Most of the studies that have investigated the potential of human enteric neural progenitors to generate an ENS have used in vitro, co-culture assays. For example, Lindley et al ${ }^{51}$ co-cultured NLBS generated from neonatal human colon with explants of embryonic mouse gut that had been removed prior to population by endogenous neural crest-derived cells, and found that the human cells engrafted and differentiated into neurons in the recipient mouse gut. NLBs generated from dissociated human mucosal tissue have also been co-cultured with embryonic chick gut or muscle from human colon and shown to form ganglia composed of neurons and glia. ${ }^{42}$ In addition, p75positive cells isolated from the ganglionic region of colon of patients with Hirschsprung disease were co-cultured with embryonic quail intestine removed prior to the arrival of neural crest-derived cells, or muscle from the aganglionic colon of Hirschsprung disease patients, and in both co-cultures, the p75-positive cells migrated into the recipient tissue. ${ }^{47}$

Two important recent studies have performed in vivo transplantations of human ENS progenitors into the mouse colon. Fattahi et $\mathrm{al}^{49}$ transplanted enteric neural progenitors derived from human pluripotent cells into the caecum of a mouse model of Hirschsprung disease, which had been treated with an immunosuppressant to prevent rejection, and found that the transplanted cells colonized the entire colon with 4 weeks. Most Hirschsprung disease model mice die within 3-4 weeks of birth, but remarkably, transplantation of enteric neural progenitors was found to prevent mortality. While this study is very exciting, it also raises several important questions. ${ }^{52}$ First, it appears that the transplanted human enteric neural progenitors migrated over 3 times faster in the postnatal mouse colon than enteric neural crest-derived cell migrate during colonization of the embryonic mouse gut; enteric neural crest-derived cells advance along the embryonic mouse gut around $35-40 \mu \mathrm{m} / \mathrm{h}^{53}$ while some of the transplanted human enteric neural progenitors injected into the caecum reached the distal colon within 4 weeks, ${ }^{49}$ which equates to a rate of advancement of $150 \mu \mathrm{m} / \mathrm{h}(10 \mathrm{~cm}$ in 4 weeks). It will therefore be very important to determine whether there is any spread to other organs of transplanted cells derived from pluripotent cells. Second, it will also be important to identify the mechanism by which the transplanted human cells prevented mortality and whether there is long-term survival and restoration of gut motility.

Cooper et al ${ }^{15}$ transplanted p75-positive cells isolated from fetal human gut tissue into the colon of immune-deficient mice, and found that the transplanted cells engrafted in around $50 \%$ of the recipient mice, and in these mice the cells spread and formed ganglia composed of neurons and glial cells. Importantly, the graft-derived neurons responded to electrical stimulation of endogenous fibers with increases in intracellular $\mathrm{Ca}^{2+}$, showing that the transplanted cells had functionally integrated into the ENS of the recipient. ${ }^{15}$ However, the spread of the transplanted cells appears to have been relative modest. 


\section{PRIORITIES FOR FUTURE RESEARCH}

The recent studies ${ }^{15,49}$ summarized above, in which human ENS cells derived from the fetal human gut and from human pluripotent stem cells were transplanted into the colon of wild-type mice and a mouse model of Hirschsprung disease, support the idea that regenerative medicine might be used to treat enteric neuropathies. Nonetheless, there are significant challenges before clinical translation, and much work remains to be done in the laboratory.

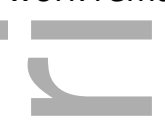

\section{Source of ENS cells to transplant into patients with enteric neuropathies}

While transplantation of ENS progenitors derived from human pluripotent stem cells rescued mortality in a mouse model of Hirschsprung disease, ${ }^{49}$ the long-term safety of these cells remains to be determined, and there would be immunological challenges associated with their use in human patients. ENS cells can be derived more efficiently from fetal human gut tissue than from postnatal human gut tissue, ${ }^{15}$ but there are ethical as well as immunological issues with the use of human fetal cells. Furthermore, there is considerable variability between fetal samples. ${ }^{15}$ Some of the inconsistency in the results of transplantation of fetal midbrain into patients with Parkinson Disease is thought to be due to variation in fetal midbrain samples. ${ }^{54,55}$ It is therefore likely that patientderived ENS progenitors will be the safest source of cells to treat enteric neuropathies. However, methods for isolating and expanding ENS cells from the infant and adult human bowel must be dramatically improved.

\section{Manipulation of human ENS cells prior to transplantation}

The efficacy of cell therapy to treat some non-ENS diseases has been shown to be augmented by genetic manipulation of the cells prior to transplantation. ${ }^{56}$ Manipulation of ENS progenitors in vitro prior to transplantation is likely to be needed to improve their ability to generate an ENS after transplantation for several reasons. ${ }^{14,57-59}$ First, the area of bowel that transplanted ENS cells will need to colonize following transplantation into humans with enteric neuropathies is significantly greater than has been demonstrated in animal models. Second, although patient-derived ENS cells offer advantages for cell transplantation, they may be reduced in number or defective in their ability to generate an ENS due to mutations that caused the disease. Studies using mouse models of Hirschsprung disease have shown that there is a reduction in the percentage of enteric neural progenitors that can be isolated using flow cytometry from the embryonic gut of the Sox $10^{\text {Dom }}$ mice compared to Sox $10^{+/+}$mice, ${ }^{31}$ while it has recently been reported that NLBs generated from the gut of embryonic Ednrb ${ }^{-/-}$mice are smaller than those from $E d n r b^{+/+}$mice. ${ }^{60}$ Many patients with 
Hirschsprung disease have RET mutations, which affects the ability of ENS precursors to migrate, proliferate and differentiate into neurons. ${ }^{61}$ Thus methods need to be developed to enhance the expansion of patient-derived cells enteric neural progenitors, ${ }^{47}$ and to correct genetic defects in their proliferative and migratory abilities prior to transplantation.

\section{Methods to introduce ENS cells into the human bowel}

Some of the commonly used methods to introduce cells into the bowel of animal models are unlikely to be practicable in humans for a variety of reasons including the size of the human bowel. Thus, methods that are minimally invasive and that can accurately deliver large numbers of cells to the affected area of bowel need to be systematically investigated. ${ }^{14}$

Transplantation of ENS cells into different bowel regions

Most recent studies have transplanted ENS cells into the colon of recipient laboratory animals. As enteric neuropathies can affect all regions of the GI tract, studies are required to examine the efficacy of transplantation of ENS cells into other regions of the GI tract, including the lower esophageal sphincter, stomach and small intestine.

\section{CONCLUDING REMARKS}

Cell therapy to treat enteric neuropathies shows great promise, particularly with recent studies using human-derived cells. However, much basic research is still required to demonstrate both the safety and feasibility of this therapy for human patients.

\section{FUNDING}

Supported by NHMRC APP1043397, APP1002506 and APP1079234.

\section{CONTRIBUTIONS}

LAS and HMY co-wrote the article.

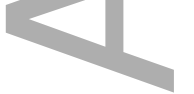

\section{CONFLICTS OF INTEREST}

No competing interests declared. 


\section{References}

1. Furness JB: The enteric nervous system and neurogastroenterology. Nat Rev Gastroenterol Hepatol 2012; 9: 286-294.

2. Goldstein AM, Thapar N, Karunaratne TB, De Giorgio R: Clinical aspects of neurointestinal disease: Pathophysiology, diagnosis, and treatment. Developmental biology 2016; 417: 217-228.

3. Knowles CH, Lindberg G, Panza E, De Giorgio R: New perspectives in the diagnosis and management of enteric neuropathies. Nat Rev Gastroenterol Hepatol 2013; 10: 206-218.

4. Barlow AJ, Wallace AS, Thapar N, Burns AJ: Critical numbers of neural crest cells are required in the pathways from the neural tube to the foregut to ensure complete enteric nervous system formation. Development (Cambridge, England) 2008; 135: 1681-1691.

5. McKeown SJ, Stamp L, Hao MM, Young HM: Hirschsprung Disease: A developmental disorder of the enteric nervous system. WIRES Dev Biol 2013; 2: 113-129.

6. Butler Tjaden NE, Trainor PA: The developmental etiology and pathogenesis of Hirschsprung disease. Transl Res 2013; 162: 1-15.

7. Obermayr F, Hotta R, Enomoto H, Young HM: Development and developmental disorders of the enteric nervous system. Nat Rev Gastroenterol Hepatol 2013; 10: 43-57.

8. Avetisyan M, Schill EM, Heuckeroth RO: Building a second brain in the bowel. The Journal of clinical investigation 2015; 125: 899-907.

9. Kulkarni S, Becker L, Pasricha PJ: Stem cell transplantation in neurodegenerative disorders of the gastrointestinal tract: future or fiction? Gut 2012; 61: 613-621.

10. Burns AJ, Thapar N: Neural stem cell therapies for enteric nervous system disorders. Nat Rev Gastroenterol Hepatol 2014; 11: 317-328.

11. Barker RA, Drouin-Ouellet J, Parmar M: Cell-based therapies for Parkinson disease-past insights and future potential. Nature reviews Neurology 2015; 11: 492-503.

12. Micci MA, Kahrig KM, Simmons RS, Sarna SK, Espejo-Navarro MR, Pasricha PJ: Neural stem cell transplantation in the stomach rescues gastric function in neuronal nitric oxide synthasedeficient mice. Gastroenterology 2005; 129: 1817-1824.

13. Young HM: Neural stem cell therapy and gastrointestinal biology. Gastroenterology 2005; 129: 2092-2095.

14. Burns AJ, Goldstein AM, Newgreen DF, Stamp L, Schafer KH, Metzger M, Hotta R, Young HM, Andrews PW, Thapar $\mathrm{N}$ et al: White paper on guidelines concerning enteric nervous system stem cell therapy for enteric neuropathies. Developmental biology 2016; 417: 229-251.

This article is protected by copyright. All rights reserved 
15. Cooper JE, Natarajan D, McCann CJ, Choudhury S, Godwin H, Burns AJ, Thapar N: In vivo transplantation of fetal human gut-derived enteric neural crest cells. Neurogastroenterol Motil 2017.

16. Kruger G, Mosher J, Bixby S, Joseph N, Iwashita T, Morrison S: Neural crest stem cells persist in the adult gut but undergo changes in self-renewal, neuronal subtype potential, and factor responsiveness. Neuron 2002; 35: 657-669.

17. Iwashita T, Kruger GM, Pardal R, Kiel MJ, Morrison SJ: Hirschsprung disease is linked to defects in neural crest stem cell function. Science (New York, NY 2003; 301: 972-976.

18. Bondurand N, Natarajan D, Thapar N, Atkins C, Pachnis V: Neuron and glia generating progenitors of the mammalian enteric nervous system isolated from foetal and postnatal gut cultures. Development (Cambridge, England) 2003; 130: 6387-6400.

19. Silva AT, Wardhaugh T, Dolatshad NF, Jones S, Saffrey MJ: Neural progenitors from isolated postnatal rat myenteric ganglia: expansion as neurospheres and differentiation in vitro. Brain research 2008; 1218: 47-53.

20. Becker L, Kulkarni S, Tiwari G, Micci MA, Pasricha PJ: Divergent fate and origin of neurospherelike bodies from different layers of the gut. American journal of physiology 2012; 302: G958965.

21. Yu H, Pan WK, Zheng BJ, Wang HJ, Chen XL, Liu Y, Gao Y: Decreased proliferative, migrative and neuro-differentiative potential of postnatal rat enteric neural crest-derived cells during culture in vitro. Experimental cell research 2016; 343: 218-222.

22. Neckel PH, Mohr R, Zhang Y, Hirt B, Just L: Comparative Microarray Analysis of Proliferating and Differentiating Murine ENS Progenitor Cells. Stem cells international 2016; 2016: 9695827.

23. Cheng LS, Hotta R, Graham HK, Nagy N, Goldstein AM, Belkind-Gerson J: Endoscopic delivery of enteric neural stem cells to treat Hirschsprung disease. Neurogastroenterol Motil 2015; 27: 1509-1514.

24. Hotta R, Cheng LS, Graham HK, Nagy N, Belkind-Gerson J, Mattheolabakis G, Amiji MM, Goldstein AM: Delivery of enteric neural progenitors with 5-HT4 agonist-loaded nanoparticles and thermosensitive hydrogel enhances cell proliferation and differentiation following transplantation in vivo. Biomaterials 2016; 88: 1-11.

25. Hotta R, Cheng LS, Graham HK, Pan W, Nagy N, Belkind-Gerson J, Goldstein AM: Isogenic enteric neural progenitor cells can replace missing neurons and glia in mice with Hirschsprung disease. Neurogastroenterol Motil 2016; 28: 498-512. 
26. Dettmann HM, Zhang Y, Wronna N, Kraushaar U, Guenther E, Mohr R, Neckel PH, Mack A, Fuchs J, Just L et al: Isolation, expansion and transplantation of postnatal murine progenitor cells of the enteric nervous system. PloS one 2014; 9: e97792.

27. Gao T, Chen H, Liu M, Ge W, Yin Q: Prospective identification and culture of rat enteric neural stem cells (ENSCs). Cytotechnology 2016; 68: 509-514.

28. Cheng LS, Graham HK, Pan WH, Nagy N, Carreon-Rodriguez A, Goldstein AM, Hotta R: Optimizing neurogenic potential of enteric neurospheres for treatment of neurointestinal diseases. J Surg Res 2016; 206: 451-459.

29. Binder E, Natarajan D, Cooper J, Kronfli R, Cananzi M, Delalande JM, McCann C, Burns AJ, Thapar N: Enteric neurospheres are not specific to neural crest cultures: implications for neural stem cell therapies. PloS one 2015; 10: e0119467.

30. Tsai YH, Murakami N, Gariepy CE: Postnatal intestinal engraftment of prospectively selected enteric neural crest stem cells in a rat model of Hirschsprung disease. Neurogastroenterol Motil 2011; 23: 362-369.

31. Walters LC, Cantrell VA, Weller KP, Mosher JT, Southard-Smith EM: Genetic background impacts developmental potential of enteric neural crest-derived progenitors in the Sox10Dom model of Hirschsprung disease. Hum Mol Genet 2010; 19: 4353-4372.

32. Cooper JE, McCann CJ, Natarajan D, Choudhury S, Boesmans W, Delalande JM, Vanden Berghe P, Burns AJ, Thapar N: In Vivo Transplantation of Enteric Neural Crest Cells into Mouse Gut; Engraftment, Functional Integration and Long-Term Safety. PloS one 2016; 11: e0147989.

33. Nishikawa R, Hotta R, Shimojima N, Shibata S, Nagoshi N, Nakamura M, Matsuzaki Y, Okano HJ, Kuroda T, Okano $\mathrm{H}$ et al: Migration and differentiation of transplanted enteric neural crestderived cells in murine model of Hirschsprung's disease. Cytotechnology 2015; 67: 661-670.

34. Findlay Q, Yap KK, Bergner AJ, Young HM, Stamp LA: Enteric neural progenitors are more efficient than brain-derived progenitors at generating neurons in the colon. American journal of physiology 2014; 307: G741-748.

35. Hotta R, Stamp LA, Foong JP, Bergner AJ, McConnell SN, Anderson RB, Enomoto H, Newgreeen DF, Obermayr F, Furness JB et al: Transplanted progenitors generate functional enteric neurons in the postnatal colon The Journal of clinical investigation 2013; 123: 1182-1191.

36. Hao MM, Lomax AE, McKeown SJ, Reid CA, Young HM, Bornstein JC: Early development of electrical excitability in the mouse enteric nervous system. J Neurosci 2012; 32: 10949-10960. 
37. Rauch U, Hansgen A, Hagl C, Holland-Cunz S, Schafer KH: Isolation and cultivation of neuronal precursor cells from the developing human enteric nervous system as a tool for cell therapy in dysganglionosis. International journal of colorectal disease 2006; 21: 554-559.

38. Almond S, Lindley RM, Kenny SE, Connell MG, Edgar DH: Characterisation and transplantation of enteric nervous system progenitor cells. Gut 2007; 56: 489-496.

39. Hetz S, Acikgoez A, Voss U, Nieber K, Holland H, Hegewald C, Till H, Metzger R, Metzger M: In vivo transplantation of neurosphere-like bodies derived from the human postnatal and adult enteric nervous system: a pilot study. PloS one 2014; 9: e93605.

40. Lindley RM, Hawcutt DB, Connell MG, Edgar DH, Kenny SE: Properties of secondary and tertiary human enteric nervous system neurospheres. Journal of pediatric surgery 2009; 44: 1249-1255; discussion 1255-1246.

41. Pan WK, Yu H, Wu AL, Gao Y, Zheng BJ, Li P, Yang WL, Huang Q, Wang HJ, Ge X: Combination of basic fibroblast growth factor and epidermal growth factor enhances proliferation and neuronal/glial differential of postnatal human enteric neurosphere cells in vitro. Neuroreport 2016; 27: 858-863.

42. Metzger M, Bareiss PM, Danker T, Wagner S, Hennenlotter J, Guenther E, Obermayr F, Stenzl A, Koenigsrainer A, Skutella T et al: Expansion and differentiation of neural progenitors derived from the human adult enteric nervous system. Gastroenterology 2009; 137: 2063-2073 e2064.

43. Fang $S, W u R$, Christensen J: Intramucosal nerve cells in human small intestine. Journal of the autonomic nervous system 1993; 44: 129-136.

44. Badizadegan K, Thomas AR, Nagy N, Ndishabandi D, Miller SA, Alessandrini A, Belkind-Gerson J, Goldstein AM: Presence of intramucosal neuroglial cells in normal and aganglionic human colon. American journal of physiology 2014; 307: G1002-1012.

45. Wilkinson DJ, Bethell GS, Shukla R, Kenny SE, Edgar DH: Isolation of Enteric Nervous System Progenitor Cells from the Aganglionic Gut of Patients with Hirschsprung's Disease. PloS one 2015; 10: e0125724.

46. Uesaka T, Nagashimada M, Enomoto H: Neuronal Differentiation in Schwann Cell Lineage Underlies Postnatal Neurogenesis in the Enteric Nervous System. J Neurosci 2015; 35: 9879 9888.

47. Rollo BN, Zhang D, Stamp LA, Menheniott TR, Stathopoulos L, Denham M, Dottori M, King SK, Hutson JM, Newgreen DF: Enteric neural cells from Hirschsprung Disease patients form ganglia in autologous aneuronal colon. Cellular and molecular gastroenterology and hepatology 2016; 2: 92-109. 
48. Kruger GM, Mosher JT, Bixby S, Joseph N, Iwashita T, Morrison SJ: Neural crest stem cells persist in the adult gut but undergo changes in self-renewal, neuronal subtype potential, and factor responsiveness. Neuron 2002; 35: 657-669.

49. Fattahi F, Steinbeck JA, Kriks S, Tchieu J, Zimmer B, Kishinevsky S, Zeltner N, Mica Y, El-Nachef $W$, Zhao Het al: Deriving human ENS lineages for cell therapy and drug discovery in Hirschsprung disease. Nature 2016; 531: 105-109.

50. Natarajan D, Cooper J, Choudhury S, Delalande JM, McCann C, Howe SJ, Thapar N, Burns AJ: Lentiviral labeling of mouse and human enteric nervous system stem cells for regenerative medicine studies. Neurogastroenterol Motil 2014; 26: 1513-1518.

51. Lindley RM, Hawcutt DB, Connell MG, Almond SN, Vannucchi MG, Faussone-Pellegrini MS, Edgar DH, Kenny SE: Human and mouse enteric nervous system neurosphere transplants regulate the function of aganglionic embryonic distal colon. Gastroenterology 2008; 135: 205216

52. Heuckeroth RO: Regeneration: Stem cells make the bowel nervous. Nature 2016; 531: 44-45.

53. Young HM, Bergner AJ, Anderson RB, Enomoto H, Milbrandt J, Newgreen DF, Whitington PM: Dynamics of neural crest-derived cell migration in the embryonic mouse gut. Developmental biology 2004; 270: 455-473.

54. Barker RA, Barrett J, Mason SL, Bjorklund A: Fetal dopaminergic transplantation trials and the future of neural grafting in Parkinson's disease. Lancet neurology 2013; 12: 84-91.

55. Barker RA, de Beaufort I: Scientific and ethical issues related to stem cell research and interventions in neurodegenerative disorders of the brain. Progress in neurobiology 2013; 110: 63-73.

56. Haider H, Mustafa A, Feng Y, Ashraf M: Genetic modification of stem cells for improved therapy of the infarcted myocardium. Mol Pharm 2011; 8: 1446-1457.

57. Hotta R, Natarajan D, Thapar N: Potential of cell therapy to treat pediatric motility disorders. Seminars in pediatric surgery 2009; 18: 263-273.

58. Metzger M, Caldwell C, Barlow AJ, Burns AJ, Thapar N: Enteric nervous system stem cells derived from human gut mucosa for the treatment of aganglionic gut disorders. Gastroenterology 2009; 136: 2214-2225

59. Micci MA, Pasricha PJ: Neural stem cells for the treatment of disorders of the enteric nervous system: strategies and challenges. Dev Dyn 2007; 236: 33-43. 
60. Fujiwara N, Miyahara K, Nakazawa-Tanaka N, Akazawa C, Yamataka A: Altered differentiation of enteric neural crest-derived cells from endothelin receptor-B null mouse model of Hirschsprung's disease. Pediatric surgery international 2016.

61. Amiel J, Sproat-Emison E, Garcia-Barcelo M, Lantieri F, Burzynski G, Borrego S, Pelet A, Arnold S, Miao X, Griseri P et al: Hirschsprung disease, associated syndromes and genetics: a review. J Med Genet 2008; 45: 1-14.

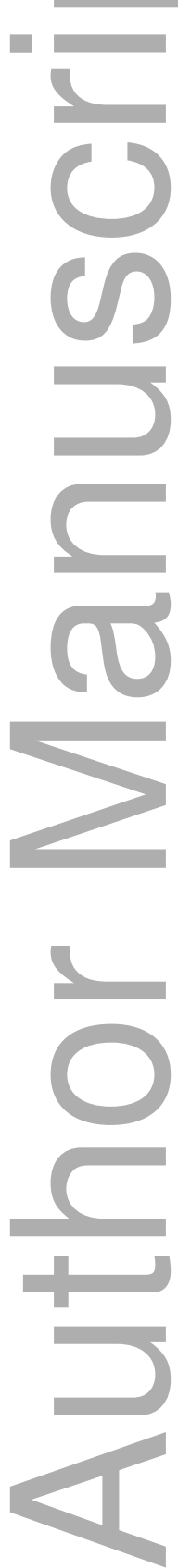




\section{University Library}

\section{- M M N E R VA A gateway to Melbourne's research publications}

Minerva Access is the Institutional Repository of The University of Melbourne

Author/s:

Stamp, LA;Young, HM

Title:

Recent advances in regenerative medicine to treat enteric neuropathies: use of human cells

Date:

2017-01-01

Citation:

Stamp, L. A. \& Young, H. M. (2017). Recent advances in regenerative medicine to treat enteric neuropathies: use of human cells. NEUROGASTROENTEROLOGY AND MOTILITY, 29 (1), https://doi.org/10.1111/nmo.12993.

Persistent Link:

http://hdl.handle.net/11343/292267 